\title{
Oral Carrageenan Induces Antigen-Dependent Oral Tolerance: Prevention of Anaphylaxis and Induction of Lymphocyte Anergy in a Murine Model of Food Allergy
}

\author{
CHRISTOPHE P. FROSSARD, CONRAD HAUSER, AND PHILIPPE A. EIGENMANN \\ Department of Pediatrics [C.P.F., P.A.E.] and Allergy Unit [C.P.F., C.H., P.A.E.], Division of \\ Immunology and Allergy, Department of Medicine, University Hospital of Geneva, Geneva, Switzerland
}

\begin{abstract}
Immunosuppressive effects of carrageenan, a high-molecularweight polysaccharide, on antibody and $\mathrm{T}$ cell responses have been previously demonstrated. However, its effect on anaphylaxis is unknown. Our objectives were to test carrageenanmediated oral tolerance induction in young mice subsequently sensitized to a common cow's milk antigen. $\mathrm{C} 3 \mathrm{H} / \mathrm{HeJ}$ mice were fed or not $\lambda$-carrageenan $(0.5 \mathrm{~g} / \mathrm{L})$ and $/$ or $0.01 \mathrm{mg} / \mathrm{mL} \beta$-lactoglobulin (BLG) for $5 \mathrm{~d}$ before oral sensitization with BLG and cholera toxin. Subsequently, the mice were challenged with BLG and symptom scores of anaphylaxis were recorded. Mesenteric lymph node cells, spleen cells, Peyer's patches cells, intraepithelial lymphocytes, and lamina propria lymphocytes were isolated and stimulated in vitro with BLG, IL-2, or left unstimulated. BLG-specific $\operatorname{IgG}, \operatorname{IgG}_{1}$, and $\operatorname{IgG}_{2 \mathrm{a}}$ antibodies were measured. Pretreatment with carrageenan and BLG, but not pretreatment with either carrageenan or BLG alone or omission of pretreatment, diminished significantly the number of anaphylactic mice after BLG challenge $(6.3 \%$ versus $53 \%$ in mice without pretreatment, $p=0.006$ ). Mesenteric lymph nodes and spleen cells from
\end{abstract}

\section{ABSTRACT}

pretreated mice proliferated less in presence of BLG or IL-2 than cells from sensitized control mice. Antigen-specific antibody production and passive cutaneous anaphylaxis was not suppressed by carrageenan and BLG pretreatment. In conclusion, carrageenan administered to young mice in conjunction with low doses of allergen before sensitization efficiently prevents anaphylaxis. (Pediatr Res 49: 417-422, 2001)

$\quad$ Abbreviations
BLG, $\beta$-lactoglobulin
CT, cholera toxin
DMEM, Dulbecco's modified eagle's medium
IEL, intraepithelial lymphocytes
LPL, lamina propria lymphocytes
MNC, mesenteric lymph node cells
PCA, passive cutaneous anaphylaxis
PPC, Peyer's patches cells
SC, spleen cells

During infancy, large amounts of potentially harmful food antigens are ingested in large quantities and, in most infants, oral tolerance is naturally acquired. Animal studies have revealed that early oral exposure to low amounts of antigen tend to promote sensitization, whereas large amounts favor tolerance induction (1). In human infants it is accepted, that potential food allergens should be completely avoided during the first months of life in infants at risk for allergy. However, these measures are only partially efficient in atopic individuals (2). Development of further strategies favoring induction of earlylife antigen-specific tolerance are strongly needed.

Received July 19, 2000; accepted October 4, 2000.

Correspondence and reprint requests: Philippe A. Eigenmann, M.D., Allergy Unit, University Hospital of Geneva, 1211 Geneva 14, Switzerland.

Supported by Novartis Nutrition, the Swiss National Research Foundation (3247118.96, 32-44502.95), the Academic Society of Geneva, the Ciba-Geigy Foundation, and the de Reuter Foundation.
Carrageenan is a high-molecular-weight galactose-based polysaccharide. When ingested it is found mostly undegraded in the gut submucosa (3), where it is taken up and cleared by macrophages (4). Although large amounts of oral carrageenan induce colitis $(5,6)$, small quantities do not appear to be toxic for the gut mucosa (3). Studies in rats have demonstrated an adjuvant effect similar to alum when carrageenan was given with ovalbumin by systemic route, but abrogation of the PCA response when given orally (7). Diminished cellular immune response mediated by carrageenan has also been demonstrated in other models. Bash and Vago fed rats with carrageenan and observed a strongly diminished cellular response in spleen cells and mesenteric lymph nodes cells (8). Rumjanek and Brent showed that intraperitoneal carrageenan suppressed $\mathrm{T}$ cell activity in mixed lymphocyte cultures and abolished mitogeninduced proliferation (9). These reports suggested an immunosuppressive effect of carrageenan. It remained undetermined, however, whether carrageenan can modify allergic reactions. 
We postulated that oral administration of carrageenan would prevent sensitization to a common food antigen and induce oral tolerance. This hypothesis was tested in an animal model of immediate-type food allergy in which signs of anaphylaxis were monitored in response to oral challenge with antigen (10). Mice were treated or not with carrageenan and low doses of BLG before oral sensitization with BLG. Tolerance induction was examined by scoring severity of anaphylaxis after antigen challenge, determination of proliferation of $\mathrm{T}$ cells from various mucosal and nonmucosal compartments, and measuring antigen-specific antibody titers.

\section{MATERIALS AND METHODS}

Mice. Four- to five-week-old female $\mathrm{C} 3 \mathrm{H} / \mathrm{HeJ}$ mice were purchased from IFFA-CREDO (L'Arbesle, France). All mice were fed cow's milk protein-free chow, and maintained in SPF conditions. The study has been approved by the institutional review board for animal experiments.

Oral sensitization to BLG. Animals were sensitized at d 0, 7 , and 14 by gavage after gastric intubation with $10 \mathrm{mg}$ BLG (Sigma Chemical Co., Buchs, Switzerland) and $10 \mu \mathrm{g}$ CT (List Biologic Laboratories, Campbell, CA, U.S.A.) in $0.2 \mathrm{M}$ $\mathrm{Na}_{2} \mathrm{HCO}_{3}$. The total volume given at each gavage was $0.4 \mathrm{~mL}$. In initial experiments, a control group was fed exclusively 10 $\mu \mathrm{g}$ CT following the same schedule.

Tolerization with carrageenan and BLG. For $5 \mathrm{~d}$ before each of three cycles of gastric sensitization $(\mathrm{d}-5-0, \mathrm{~d} 2-7, \mathrm{~d}$ 9-14), mice were given water containing $\lambda$-carrageenan 0.5 g/L (Sigma Chemical Co., Buchs, Switzerland), and BLG 0.01 $\mathrm{mg} / \mathrm{L}$ ad libitum (pretreatment). BLG was added to favor antigen-specific tolerance induction. In control groups, mice were given exclusively either water containing BLG 0.01 $\mathrm{mg} / \mathrm{L}$, or carrageenan $0.5 \mathrm{~g} / \mathrm{L}$ ad libitum for $5 \mathrm{~d}$. To study oral tolerance acquisition in already sensitized mice (secondary tolerance), a group of mice received $0.5 \mathrm{~g} / \mathrm{L} \lambda$-carrageenan in water containing BLG $0.01 \mathrm{mg} / \mathrm{L}$ for a period of $5 \mathrm{~d}$ before antigen challenge. Each condition included four to six mice, all experiments were repeated at least twice. The procedures are detailed in Figure 1.

Antigen challenge. On d 28, all mice were challenged by intragastric gavage with $10 \mathrm{mg}$ BLG in $0.4 \mathrm{~mL} 0.2 \mathrm{M}$ $\mathrm{Na}_{2} \mathrm{HCO}_{3}$. Signs were observed and graded using the reaction score outlined in Table 1 . Mice with scores $\geq 2$ were considered as having anaphylaxis. For ethical reasons, mice with severe reactions (score 3 ) were immediately killed, otherwise, all mice were killed $30 \mathrm{~min}$ after the challenge. Following

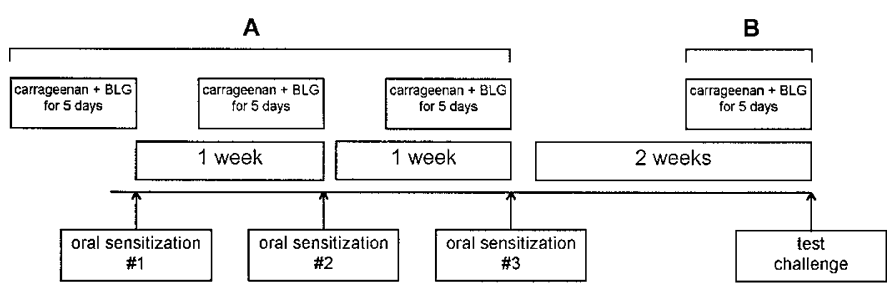

Figure 1. Schedules for sensitizations with BLG and cholera toxin, test challenges, and feedings of carrageenan and BLG for primary tolerance induction $(A)$, and secondary tolerance induction $(B)$.
Table 1. Anaphylaxis reaction score

\begin{tabular}{cll}
\hline Score & & \\
\hline 0 & No reactions & Normal activity \\
1 & Mild reactions & Decreased activity \\
& & Random scratching \\
& Myocloni \\
& & Reversibility of symptoms within $5^{\prime}$ \\
& & Marked decreased reactivity \\
2 & Moderate reactions & Continuous scratching \\
& & Abnormal breathing \\
& & Reversibility of symptoms within 10' \\
& & Low reactivity or absence of reactivity \\
3 & Severe reactions & Abnormal breathing \\
& & Death, or no reversibility of symptoms \\
& & within 15' \\
\hline
\end{tabular}

sacrifice, blood was collected by cardiac puncture into EDTAcontaining tubes, and plasma was obtained by centrifugation for $10 \mathrm{~min}$ at $1000 \times \mathrm{g}$ for histamine measurement. All samples were kept at $4^{\circ} \mathrm{C}$, and subsequently frozen until histamine determination by commercial ELISA kit (Immunotech, Marseille, France).

Mesenteric lymph nodes, Peyer's patches, and spleen cells proliferation. MNC and PPC were re-suspended in DMEM (Life Technologies, Basel, Switzerland). SC were additionally incubated for $5 \mathrm{~min}$ in Tris-buffered $\mathrm{NH}_{4} \mathrm{Cl}$ to remove red blood cells. Mononuclear cells $\left(2 \times 10^{5}\right.$ cells/well $)$ were incubated in complete DMEM with $10 \%$ fetal calf, penicillin/ streptomycin, L-glutamin, 2-mercaptoethanol, and nonessential amino-acids (Life Technologies, Basel, Switzerland). Culture conditions were either alone, in media supplemented with $40 \mathrm{U} / \mathrm{mL} \mathrm{IL-2}$, or in presence of BLG $(0.25 \mathrm{mg} / \mathrm{mL}, 20$ $\mu \mathrm{L} /$ well). The cells were pulsed on d 5 of culture with 1 $\mu \mathrm{Ci} /$ well ${ }^{3} \mathrm{H}$-labeled thymidine (Amersham, Zürich, Switzerland) for $18 \mathrm{~h}$ and harvested.

Isolation of intraepithelial lymphocytes and lamina propria lymphocytes. IEL and LPL were isolated as described (11). In brief, epithelium of the small intestine was gently scrapped after removing Peyer's patches. The cell suspension was filtered through a nylon wool column, followed by two cycles of centrifugation with $67 \%$ Percoll to isolate IEL. For LPL isolation, the submucosa was minced and incubated in collagenase (Sigma Chemical Co., Buchs, Switzerland).

Cell surface analysis. Isolated cell populations were stained for flow cytometric analysis with the following fluorochromelabeled antibodies: anti-CD3, anti-CD4, anti-CD8, anti-TCR $\alpha / \beta$, anti-TCR $\gamma / \delta$, anti- $\alpha_{\mathrm{IEL} \beta} 7$ (all obtained from Pharmingen, Basel, Switzerland).

ELISA for BLG-specific serum antibody. Sera were obtained for determination of BLG-specific $\mathrm{IgG}, \mathrm{IgG}_{1}$, and $\mathrm{IgG}_{2}$ a levels after antigen challenge. Ten micrograms per milliliter BLG was coated overnight in MaxiSorp ${ }^{\mathrm{TM}}$ microtiter plates (Nunc, Roskilde, Denmark) followed by incubation of $50 \mu \mathrm{L}$ of mouse serum (at $1: 50 \mathrm{vol} / \mathrm{vol}$ ). Either $0.5 \mu \mathrm{g} / \mathrm{mL}$ goat anti-mouse $\mathrm{IgG}_{1}$, or rat anti-mouse $\mathrm{IgG}_{2 \mathrm{a}}$ peroxidase-labeled antibodies (Southern Biotechnologies, Birmingham, AL, U.S.A.) were added and incubated for $2 \mathrm{~h}$. OD was measured at $490 \mathrm{~nm}$ with an automated ELISA plate reader (Molecular Device Corporation, Menlo Park, CA, U.S.A.). All sera were 
tested in duplicate. Results were expressed as arbitrary units, with pooled sera from immunized mice used as a reference serum. BLG-specific IgG was measured by coating plates overnight at $4^{\circ} \mathrm{C}$ with $10 \mu \mathrm{g} / \mathrm{mL}$ goat anti-mouse IgG (Southern Biotechnologies, Birmingham, AL, U.S.A.), followed by incubation with serum samples (at 1:100) for $2 \mathrm{~h}$ at $37^{\circ} \mathrm{C}$, and $10 \mu \mathrm{g} / \mathrm{mL}$ biotinylated BLG for $2 \mathrm{~h}$. After adding streptavidinperoxidase IgG (Southern Biotechnologies) at 1:2000, plates were developed with o-Phenylenediamine. Results were expressed as a ratio compared with the specific antibody level in pooled sera from sensitized mice with anaphylaxis at antigen challenge.

Statistical analysis. Values between groups were analyzed by the Wilcoxon rank signed test for nonparametric unpaired data.

\section{RESULTS}

Mice sensitized to BLG develop anaphylaxis in response to antigen challenge. Gastric antigen challenge elicited anaphylactic reactions in mice sensitized with CT and BLG. Signs of anaphylaxis were graded according a standardized score (Table 1). Most mice had anaphylaxis within $10 \mathrm{~min}$ of the challenge. Table 2 summarizes the scores after BLG challenge in a group of mice sensitized with CT and BLG and in a group given CT alone (control mice). An anaphylaxis score of $\geq 2$ was significantly more frequent in sensitized than in control mice. Anaphylaxis scores of $\geq 2$ correlated with elevated plasma histamine levels. Moreover, PCA was positive only in mice sensitized with CT and BLG (not shown). To validate further experiments, at least half of the sensitized mice (sensitized mice without tolerization procedures) in a same experiment had to react with a score $\geq 2$.

Carrageenan with low doses of BLG induces primary tolerance. Using this animal model, we tested the effect of $\lambda$-carrageenan $0.5 \mathrm{~g} / \mathrm{L}$ given with low doses of BLG $(0.01$ $\mathrm{mg} / \mathrm{L}$ ) (pretreated) on tolerance induction. Only 1 out of a total of 16 mice (6.3\%) treated with carrageenan and BLG before sensitization with CT and BLG reacted (Table 3) whereas in the sensitized group (not pretreated) $8 / 15(53 \%)$ had anaphylaxis score $\geq 2(p=0.006)$. Plasma was assayed for histamine. In mice pretreated with carrageenan, histamine levels were lower (mean histamine value \pm SEM: $132.7 \pm 22.8 \mathrm{ng} / \mathrm{mL}$ ) than in mice without pretreatment (mean histamine value \pm SEM: $322.8 \pm 89.7 \mathrm{ng} / \mathrm{mL})$ but did not reach significance $(p=$ $0.07)$.

Table 2. Number of mice from a BLG-sensitized group and a control mice group (receiving only cholera toxin) assigned to anaphylaxis scores $0-3$ after BLG challenge. Representative results from more than three different experiments are shown.

\begin{tabular}{lllll}
\hline & \multicolumn{4}{c}{ Anaphylaxis score } \\
\cline { 2 - 5 } & 0 & 1 & 2 & 3 \\
\hline BLG-sensitized mice & 2 & 1 & 1 & 6 \\
Control mice & 6 & 0 & 0 & 0
\end{tabular}

$p<0.01$ by comparing both groups for the occurrence anaphylaxis score $\geq 2$.
Table 3. Number of mice from a group pretreated with carrageenan and BLG before sensitization with BLG (pretreated), and from a group without pretreatment (not pretreated) assigned to anaphylaxis scores $0-3$ after BLG challenge. Pooled results from three independent experiments are shown.

\begin{tabular}{lrccc}
\hline & \multicolumn{4}{c}{ Anaphylaxis score } \\
\cline { 2 - 5 } & 0 & 1 & 2 & 3 \\
\hline Pretreated & 11 & 4 & 0 & 1 \\
Not pretreated & 2 & 5 & 6 & 2 \\
\hline
\end{tabular}

$p=0.006$ by comparing the number of mice with anaphylaxis score $\geq 2$ and mice with anaphylaxis score $\leq 1$ in both groups.

To verify the synergistic effect of carrageenan and BLG for tolerance induction, a group of mice was pretreated exclusively with BLG $(0.01 \mathrm{mg} / \mathrm{mL})$ or with carrageenan $(0.5 \mathrm{~g} / \mathrm{L})$. In either group, anaphylaxis scores after antigen challenge were similar to mice sensitized with BLG without pretreatment $(5 / 6$ in the group receiving BLG, 5/5 in the group receiving carrageenan alone).

We further explored whether tolerance could be induced by carrageenan plus BLG in already sensitized animals (secondary tolerance induction). A group of animals was first sensitized to BLG and then given a single feeding of carrageenan $(0.5 \mathrm{~g} / \mathrm{L})$ with BLG $(0.01 \mathrm{mg} / \mathrm{mL})$ (prechallenge) before challenge with BLG. This group reacted similarly after antigen challenge $(50 \%$ with anaphylaxis score $\geq 2)$ than the sensitized control group (not pretreated) $(61.5 \%$ with anaphylaxis score 2$)(p=$ NS) (Table 4).

Carrageenan induces modulation of antigen and IL-2induced cell proliferation. Mononuclear cells were isolated from three lymphoid compartments: the spleen, mesenteric lymph nodes, and Peyer's patches. MNC of carrageenan and BLG pretreated mice (carrageenan + BLG) proliferated significantly less in media with IL-2 than MNC of naive or sensitized mice (Fig. 2, $p<0.05$ ). IL-2-induced proliferation of MNC of both naive and sensitized mice was high. The degree of proliferation was not different between these two latter groups. Similar results were seen in SC, with significant differences between sensitized and pretreated mice for antigeninduced proliferation. IL-2-induced proliferation was slightly higher in PPC from pretreated and sensitized mice than in PPC from naive mice.

When cell proliferation in response to BLG was compared between the different groups of mice, the proliferation pattern was similar in cells from all three compartments (SC, MNC,

Table 4. Number of mice from a group first sensitized with $B L G$ and then fed with carrageenan and BLG before challenge (prechallenge), and from a group without pretreatment but sensitized to BLG (not pretreated) assigned to anaphylaxis scores $0-3$ after BLG challenge. Pooled results from three different experiments are shown.

\begin{tabular}{lllll}
\hline & \multicolumn{4}{c}{ Anaphylaxis score } \\
\cline { 2 - 5 } & 0 & 1 & 2 & 3 \\
\hline Prechallenge & 6 & 1 & 4 & 3 \\
Not pretreated & 2 & 3 & 5 & 3 \\
\hline
\end{tabular}

$p=$ NS by comparing the number of mice with anaphylaxis score $\geq 2$ and mice anaphylaxis score $\leq 1$ in both groups. 

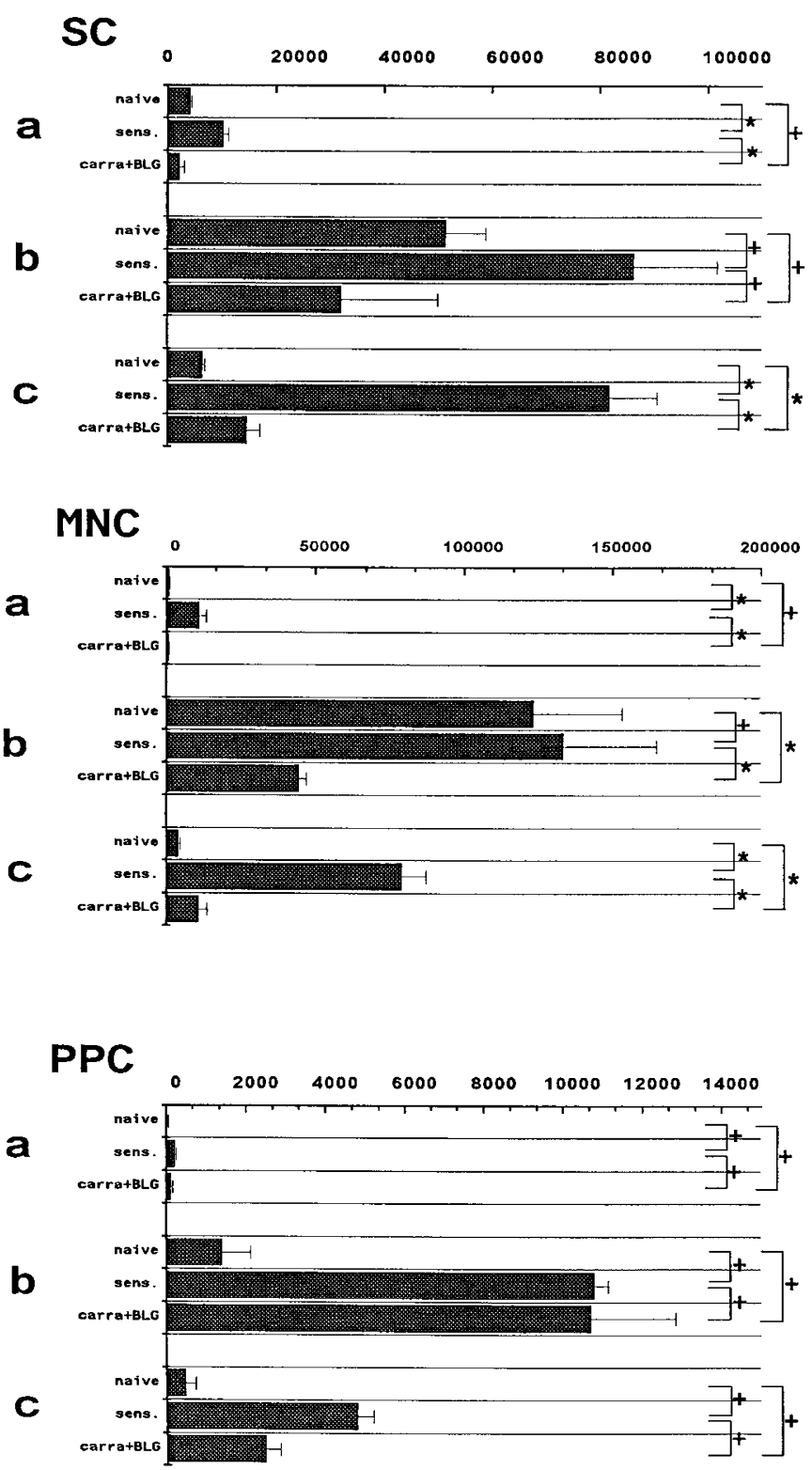

Figure 2. Proliferation of cells obtained from lymphoid structures in the gut. Four groups of mice were examined: naive mice, mice sensitized with BLG and cholera toxin (sens.), and mice sensitized with BLG and cholera toxin and pretreated with carrageenan $(0.5 \mathrm{mg} / \mathrm{mL})$ and BLG $(0.01 \mathrm{mg} / \mathrm{mL})$ $($ carra $+B L G)$. Cells were incubated either in media alone $(a)$, in media supplemented with IL-2 $40 \mathrm{U} / \mathrm{mL}(b)$, or in media with $0.25 \mathrm{mg} / \mathrm{mL} \beta$-lactoglobulin $(c)$. Cells from four mice per group were pooled, and each determination was done in triplicate. ${ }^{*} p<0.05 ;+p=$ NS.

PPC), unlike IL-2-induced proliferation. Antigen-dependent proliferation was higher in cells from sensitized mice than from naive mice in SC, and MNC $(p<0.05)$. In contrast, antigeninduced cell proliferation was lower in pretreated than sensitized mice but always higher than in naive mice. The differences were significant in SC and MNC but not PPC.

The lymphocyte subset distribution in different lymphoid compartments of the gut is not modified by carrageenan or by sensitization to BLG. PPC, MNC, and IEL isolated from naive mice, or pretreated mice were stained with lymphocyte surface markers (Fig. 3). The number of cells expressing CD3, CD4, CD8, $\alpha 4 \beta 7$ integrin, or $\alpha_{\mathrm{IEL}} \beta 7$ integrin in naive mice and
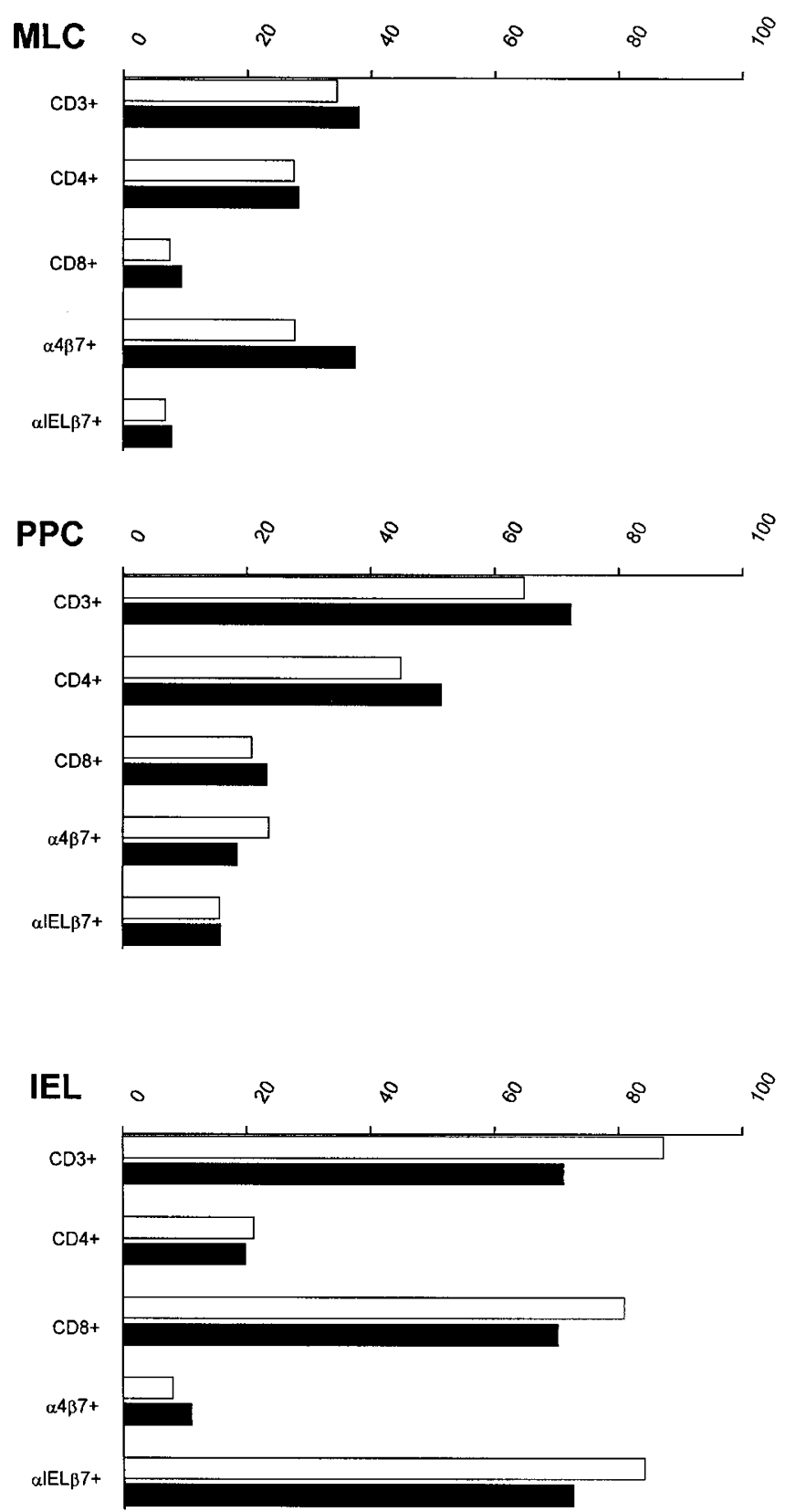

Figure 3. Flow cytometric analysis of cells isolated from PPC, mesenteric lymph nodes (MLC), and IEL for CD3, CD4, CD8, $\alpha 4 \beta 7$, and $\alpha \operatorname{IEL} \beta 7+$. Data were obtained from pooled cells from either four carrageenan-treated mice (white columns), or pooled cells from four naive mice (black columns). The results shown are representative of at least three experiments. Results are expressed as the percentage of total cells obtained.

pretreated mice were similar, whereby the proportions of the different subsets varied in function of their origin (MLN, PPC, IEL).

BLG-specific antibodies. Serum obtained after antigen challenge was assayed for BLG-specific antibodies (Fig. 4). BLGspecific IgG antibodies were present in both carrageenan pretreated and sensitized mice. The mean levels of $\mathrm{IgG}, \operatorname{IgG}_{1}$ and $\mathrm{IgG}_{2 \mathrm{a}}$ antibodies were somewhat higher in pretreated than in sensitized mice but without significant difference. In contrast, specific $\mathrm{IgG}, \mathrm{IgG}_{1}$ and $\mathrm{IgG}_{2 \mathrm{a}}$ from both groups of mice were significantly higher than from naive mice. Furthermore, PCA scores were similar in both groups of mice. 
[ratio to reference serum]

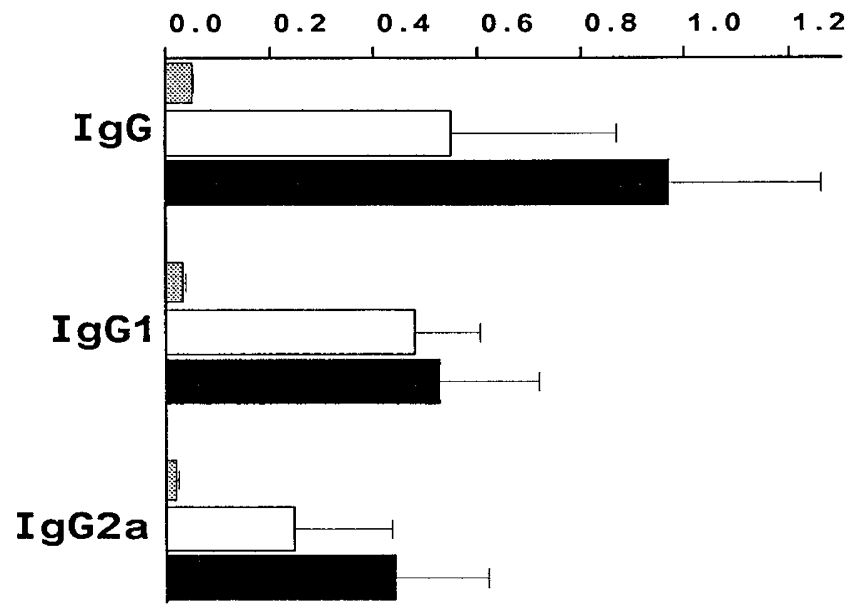

Figure 4. BLG-specific antibody response ( $\left(g G, \operatorname{IgG}_{1}, \operatorname{IgG}_{2 \mathrm{a}}\right)$ measured by ELISA in serum obtained at antigen gavage. Titers obtained in naive mice are expressed in gray columns, carrageenan-treated mice are in white columns, and titers in sensitized mice in dark columns. The results are compared with titers from a reference serum (sera pooled from sensitized mice with strong anaphylactic reactions), and expressed as a ratio. Sera from four mice per group were pooled, and each measure was done in duplicate. The results shown are representative of at least three experiments. $p=\mathrm{NS}$ for statistical analysis of $\mathrm{IgG}, \mathrm{IgG}_{1}$, and $\mathrm{IgG}_{2 \mathrm{a}}$ levels between carrageenan treated mice and sensitized mice.

\section{DISCUSSION}

Carrageenan, administered with low amounts of BLG to achieve antigen-specific tolerance, could prevent anaphylaxis in mice subsequently sensitized to BLG together with the potent mucosal adjuvant CT. Tolerance was induced only when both carrageenan and antigen were fed together before sensitization to BLG. Thus, nonspecific immune suppression due to feeding of carrageenan can be excluded. However, carrageenan was required for tolerance induction because pretreatment of mice with BLG alone before sensitization did not induce oral tolerance.

Besides oral tolerance induction with regard to anaphylaxis, pretreatment with carrageenan and BLG before sensitization was associated with a significantly reduced antigen-induced $\mathrm{T}$ cell proliferation in SC and MNC compared with BLG sensitization. Interestingly, cells deriving from one of the gutassociated lymphoid tissue compartments (i.e. MNC) and from spleen showed the same pattern. IL-2-induced cell proliferation differed in the two gut-associated lymphoid tissues, i.e. MNC and PPC. Compared with cells from sensitized mice, IL-2induced proliferation was decreased in MNC but unchanged in PPC from mice pretreated with carrageenan and BLG. The surface marker studies, including CD25, did not disclose any significant change between pretreated and naive mice. Tolerance to common antigens in the gut, and breaches in tolerance leading to diseases results from complex interaction between the different cell population, and is far from being completely understood [reviewed in (12)]. The significance of the change in lymphocyte proliferation in our experiments is unknown but has identified SC and MNC as potential candidate cells medi- ating the tolerizing effect. Transfer of these subsets into naive mice may provide information on their function in this model.

Previous studies reported similarly diminished lymphocyte responsiveness in presence of carrageenan, without a visible modification, or a toxic effect on intraepithelial lymphocytes or lymph node $\mathrm{T}$ cells $(3,7,13)$. To explain low lymphocyte responsiveness, several authors implicated a role for macrophages $(8,14)$. Morphologic modifications of these cells may mostly be explained by delayed degradation of the highmolecular-weight polysaccharides. Thus carrageenancontaining macrophages may either present antigen in a way that favors induction of tolerance or may secrete factors that may modify the presentation of adjacent antigen presenting cells (8).

In contrast to suppressed $\mathrm{T}$ cell proliferation in pretreated mice, we did not see changes in BLG-specific IgG titers or in PCA response in either group. Our results are in apparent conflict with those from other groups but may be explained by differences in readout and treatment protocols. Coste et al. indirectly measured the antibody response by PCA in iotacarrageenan-treated mice. PCA tests were negative in treated groups, suggesting an absence of "reaginic" antibodies (7). However, no antibody titers were reported in these studies. In studies reported by Nicklin and Miller, rats were administered carrageenan for $90 \mathrm{~d}$, followed by parenteral immunization with sheep red blood cells, which resulted in abolished antigenspecific antibody response in the treated groups (3). Split tolerance, i.e. tolerance with regard to one versus a second readout, has been known for years. In our protocol, we were able to induce tolerance with regard to anaphylaxis and a related change in lymphocyte proliferation but not with regard to PCA and antibody titers. It is currently unknown whether there is a hierarchy among the reports regarding the ease of tolerance induction with a given tolerization protocol and/or whether different protocols vary with regard to their strength in providing the signal(s) for tolerance induction. Whether functionally distinct types of antigen-specific antibodies of the same isotype were generated in the pretreated versus sensitized mice, as described earlier (15), remains to be determined. We believe, however, that a simple shift in Th1/Th2 balance is unlikely to explain our results because neither specific antibodies of the $\mathrm{G}_{2 \mathrm{a}}$ isotype indicative of Th1 cell activity nor specific antibodies of the $G_{1}$ isotype indicative of Th2 cell activity differed significantly between sensitized and tolerized mice.

Several authors reported carrageenan-induced colitis in animals given $1.5 \mathrm{~g} / \mathrm{L}$ carrageenan or more $(5,16)$. However, in our studies no symptoms, or macroscopic alteration, suggesting colitis were observed in animals given $0.5 \mathrm{~g} / \mathrm{L}$ carrageenan. These findings may have a favorable implication for therapeutic application of carrageenan as tolerance inductor. In fact, high-molecular-weight polysaccharides are reported to be nontoxic in moderate amounts, and are largely present in many foods (17). Supplementing the food of young infants with high-molecular-weight polysaccharides such as carrageenan would represent an easy food ingredient to favor oral tolerance induction. Further studies are required to investigate this nutritional intervention strategy for oral tolerance induction. 
Acknowledgments. The authors thank Laurence Tropia for technical assistance, and Prof. A. de Weck and Dr. H. Schneider for continuous support and advice.

\section{REFERENCES}

1. Strobel S, Mowat AM 1998 Immune responses to dietary antigens: oral tolerance Immunol Today 19:173-81

2. Zeiger RS, Heller S 1995 The development and prediction of atopy in high-risk children: follow-up at age seven years in a prospective randomized study of combined maternal and infant food allergen avoidance. J Allergy Clin Immunol 95:1179-1190

3. Nicklin S, Miller K 1984 Effect of orally administered food-grade carrageenans on antibody-mediated and cell-mediated immunity in the inbred rat. Food Chem Toxico 22:615-621

4. Thomson AW, Fowler EF, Pugh-Humphreys RG 1979 Immunopharmacology of the macrophage-toxic agent carrageenan. Int J Immunopharmacol 1:247-261

5. Anver MR, Cohen J 1976 Animal model of human disease. ulcerative colitis. anima model: ulcerative colitis induced in guinea pigs with degraded carrageenan. Am J Pathol 84:431-434

6. Watt J, Marcus R 1973 Experimental ulcerative disease of the colon in animals. Gut $14: 506-510$
7. Coste M, Dubuquoy C, Tomé D 1989 Effect of systemic and orally administered ioto-carrageenan on ovalbumin-specific antibody response in the rat. Int Arch Allergy Appl Immunol 88:474-476

8. Bash JA, Vago JR 1980 Carrageenan-induced suppression of T lymphocyte proliferation in the rat: in vivo suppression induced by oral administration. J Reticuloendothel Soc 28:213-221

9. Rumjanek VM, Brent L 1978 Immunosuppressive activity of carrageenan for cellmediated responses in the mouse. Transplantation 26:113-118

10. Snider DP, Marshall JS, Perdue MH, Liang H 1994 Production of IgE antibody and allergic sensitization of intestinal and peripheral tissues after oral immunization with protein antigen and cholera toxin. J Immunol 153:647-657

11. Lefrancois L 1987 Carbohydrate differentiation antigens of murine T cells: expression on intestinal lymphocytes and intestinal epithelium. J Immunol 138:3375-3384

12. Abreu-Martin MT, Targan SR 1996 Regulation of immune responses of the intestinal mucosa. Crit Rev Immunol 16:277-309

13. Sakemi T, Kuroiwa A, Nomoto K 1980 Effect of carrageenan on the induction of cell-mediated cytotoxic responses in vivo. Immunology 41:297-302

14. Rumjanek VM, Watson SR, Sljivic VS 1977 A re-evaluation of the role of macrophages in carrageenan-induced immunosuppression. Immunology 33:423-432

15. Faquim-Mauro EL, Coffman RL, Abrahamsohn IA, Macedo MS 1999 Cutting edge: mouse IgG1 antibodies comprise two functionally distinct types that are differentially regulated by IL-4 and IL-12. J Immunol 163:3572-3576

16. Watt J, Marcus R 1971 Carrageenan-induced ulceration of the large intestine in the guinea pig. Gut 12:164-171

17. Weiner ML 1991 Toxicological properties of carrageenan. Agents Actions $32: 46-51$ 